\title{
A \\ CESSO DE FAMÍlIAS POBRES AOS SERVIÇOS DE SANEAMENTO: SUGESTÃO DE UM PROGRAMA COM CONTEÚDO SOCIAL/AMBIENTAL
}

DOI: $10.12957 /$ synthesis.2015.25621

THOMPSON ALMEIDA ANDRADE*

\begin{abstract}
Resumo: Este artigo está focado na constatação de que as famílias pobres no Brasil têm menos acesso aos serviços de saneamento do que as demais famílias e de que há necessidade da adoção de uma ação social que cuide de aspectos da oferta deste serviço (aumentando os investimentos e as conexões) e da demanda (propiciando condições financeiras que permitam que os pobres satisfaçam esta necessidade). $\mathrm{O}$ artigo faz referência à experiência de projetos de saneamento financiados com o uso do instrumento chamado "output-based aid" (OBA), o qual tem se mostrado útil para estimular os investimentos na forma requerida, qual seja, aumentar as conexões. $\mathrm{Na}$ seção de sugestões, além do uso de projetos tipo OBA, recomenda-se adotar uma bolsasaneamento, um complemento de renda concedido às famílias pobres, que permitiria o acesso das mesmas aos serviços de saneamento.
\end{abstract}

Palavra-chave: Saneamento Urbano. Política Social no Brasil. Desigualdades Sociais.

Poor families' access to sanitation services: suggestion of a program with social/ environmental content

Abstract: This article focuses on the finding that poor households in Brazil have less access to sanitation services than other families and that there is need to adopt a social action to take care of aspects of the supply of this service (increasing investment and connections) and demand (providing financial conditions that enable the poor meet this need). The article refers to the experience of sanitation projects financed using the financial tool called "output-based aid" (OBA), which has proved useful to induce investments in the required manner, that is, to increase the connections. In the section of suggestions, besides the recommendation of employing the use of OBA type projects, it is suggested the adoption of the "bolsa saneamento", an income supplement granted to poor families that would allow them to pay their sewage bills.

Keywords: Urban Sanitation. Social Policy in Brazil. Social Inequalities.

* Prof. Titular da Faculdade de Ciências Econômicas da Uerj. Prof. do mestrado em Economia Empresarial da UCAM.

\section{INTRODUÇÃO}

O objetivo deste trabalho é discutir o acesso das famílias mais pobres aos serviços da infraestrutura social, particularmente aos de coleta e tratamento de esgoto no Brasil. Sabe-se que a não coleta e, consequentemente, o não tratamento das águas servidas apresentam externalidades negativas sérias

do ponto de vista da incidência de problemas de saúde na população de qualquer país, sendo responsáveis diretos por doenças e mortes. Além da degradação do meio ambiente, estes reflexos danosos poderiam ser evitados se o governo desse uma prioridade maior ao tema nas políticas que adota. ${ }^{1}$

[SYN]THESIS, Rio de Janeiro, vol.8, n 1, 2015, p. 9 - 20 
Este trabalho primeiramente mostra e discute algumas estatísticas para demonstrar que o governo brasileiro precisa ampliar, do ponto de vista da oferta, os investimentos na expansão das redes de coleta de esgoto no país e, do lado da demanda, melhor focar os recursos que tem disponibilizado para permitir que as famílias pobres (as que têm o pior acesso aos serviços de saneamento) possam conectar as suas residências às redes de coleta e tratamento de esgoto, de modo a evitar a poluição maior do meio ambiente. A segunda parte do trabalho examina alguns instrumentos que podem ajudar a consecução destes objetivos.

\section{As Estatísticas dos Serviços de Infraestrutura Social no Brasil: O CASO do Esgoto}

Por serviços da infraestrutura social, este trabalho compreende os que se referem ao abastecimento de água potável e da coleta e tratamento das águas servidas, a energia elétrica residencial, a coleta de lixo e os serviços telefônicos, que podem ser considerados como básicos no mundo moderno, essenciais para uma existência digna.

A Tabela 1 mostra o nível de atendimento (porcentagem da população e dos domicílios) no Brasil e sua evolução no período 1992-2009.

Tabela 1 - Porcentagem da População Atendida por Serviços da Infraestrutura Social no Brasil, 1992/2009

\begin{tabular}{llllllr}
\hline Ano & $\begin{array}{c}\text { Eletri- } \\
\text { cidade }\end{array}$ & Água & Lixo & Esgoto & $\begin{array}{c}\text { Telefone } \\
\text { fixo }\end{array}$ & $\begin{array}{c}\text { Telefone } \\
\text { móvel }\end{array}$ \\
\hline 1992 & 87,45 & 65,93 & 59,82 & 36,02 & 17,21 & - \\
1993 & 88,62 & 66,86 & 61,23 & 36,07 & 17,85 & - \\
1995 & 90,60 & 68,97 & 62,87 & 36,83 & 20,27 & - \\
1996 & 91,89 & 72,15 & 63,17 & 37,77 & 23,35 & - \\
1997 & 62,45 & 71,75 & 66,31 & 38,52 & 26,18 & - \\
1998 & 93,30 & 73,18 & 67,95 & 40,08 & 30,16 & - \\
1999 & 94,12 & 74,19 & 69,85 & 41,20 & 35,80 & - \\
2001 & 95,33 & 75,89 & 73,56 & 43,02 & 50,00 & 30,79 \\
2002 & 96,10 & 77,14 & 74,44 & 43,83 & 51,52 & 34,46 \\
2003 & 96,49 & 77,74 & 76,17 & 45,38 & 49,61 & 38,57 \\
2004 & 96,78 & 78,66 & 76,22 & 46,10 & 48,23 & 48,88 \\
2005 & 97,17 & 78,96 & 77,64 & 46,20 & 47,37 & 61,40 \\
2006 & 97,70 & 80,32 & 78,77 & 46,54 & 46,08 & 65,81 \\
2007 & 98,15 & 80,95 & 79,12 & 49,18 & 44,73 & 70,04 \\
2008 & 98,58 & 81,78 & 79,09 & 50,92 & 44,08 & 78,58 \\
2009 & 98,91 & 82,71 & 81,89 & 51,04 & 42,87 & 81,55 \\
\hline
\end{tabular}

Fonte dos dados originais: PNAD/IBGE. Cálculos feitos pelo Centro de Políticas Sociais/FGV. 
Como se pode ver na tabela, apenas os serviços de esgoto ainda não atendiam em 2009 a uma parcela grande dos brasileiros, atingindo tão somente pouco mais de 50 por cento dos domicílios. ${ }^{2}$ Ainda será necessário um grande esforço de investimentos nesta área para que a situação não continue tão precária. É bem verdade que os demais serviços, como o abastecimento de água potável e a coleta de lixo, ainda requerem uma ampliação considerável para que uma universalização dos mesmos atinja plenamente a população brasileira.

O índice de $51,04 \%$ da população atendida por serviços de esgoto refere-se a uma média para o país, mas há uma discrepância para baixo, regionalmente, para este indicador, porque as regiões menos desenvolvidas do Brasil, como o Norte e Nordeste, e as regiões Sul e CentroOeste, exibem índices bem menores, como mostrado na Tabela 2.

Tabela 2 - Porcentagem da População Brasileira Atendida por Serviços de Esgoto, 2009

\begin{tabular}{lccr}
\hline Região & Taxa de acesso & $\begin{array}{c}\text { \% da População } \\
\text { com acesso }\end{array}$ & $\begin{array}{r}\text { População } \\
\text { com acesso }\end{array}$ \\
\hline Norte & 9,56 & 1,24 & 1.187 .398 \\
Nordeste & 29,22 & 16,39 & 15.743 .816 \\
Sudeste & 80,85 & 67,58 & 64.915 .437 \\
Sul & 33,31 & 9,60 & 9.219 .264 \\
C.Oeste & 35,85 & 5,20 & 4.992 .988 \\
Brasil & 51,04 & 100,00 & 96.058 .903 \\
\hline
\end{tabular}

Fonte dos dados originais: PNAD/IBGE. Cálculos feitos pelo Centro de Políticas Sociais/FGV.

Verifica-se na Tabela 2 que apenas 9,56 por cento da população no Norte e 29,22 por cento da população no Nordeste do Brasil, além de 33,31 por cento e 35,85 por cento, respectivamente, para as regiões Sul e Centro-Oeste, se beneficiam de algum tipo de acesso aos serviços de esgoto, os quais certamente estão mais concentrados na região Sudeste, a mais desenvolvida do país. A tabela permite ainda que seja observado que, de quase 100 milhões de pessoas com acesso a estes serviços, 64 milhões residem no Sudeste $(67,58$ por cento das com acesso); os outros quase 30 milhões de brasileiros com acesso encontram-se nas outras quatro regiões. Entretanto, vale lembrar que, como a população brasileira em 2009 era de aproximadamente 180 milhões de habitantes, mais de 80 milhões residiam em domicílios sem acesso aos serviços de esgoto.

Para estes, certamente, além da indisponibilidade da oferta dos serviços, o problema básico é a incapacidade de a população pagar pelos serviços de esgoto por carência de renda. Isto fica claro observando-se os dados da Tabela 3.

Conforme se pode ver na Tabela 3, os serviços de esgoto atendem principalmente às pessoas das mais altas classes, ou seja, A, B e C. As de classe média 
Tabela 3 - Acesso da População Brasileira aos Serviços de Esgoto, por Classe de Renda, em 2009

\begin{tabular}{lccc}
\hline Região & Taxa de acesso & $\begin{array}{c}\text { \% da População } \\
\text { com acesso }\end{array}$ & $\begin{array}{c}\text { População } \\
\text { com acesso }\end{array}$ \\
\hline Classe E & 30,64 & 9,2 & 8.836 .990 \\
Classe D & 40,45 & 18,72 & 17.980 .847 \\
Classe C & 57,79 & 57,11 & 54.863 .649 \\
Classe A,B & 72,00 & 14,97 & 14.377 .417 \\
Brasil & 51,04 & 100,00 & 96.058 .903 \\
\hline
\end{tabular}

Fonte dos dados originais: PNAD/IBGE. Cálculos feitos pelo Centro de Políticas Sociais/FGV.

baixa e os pobres, as classes D e E, são apenas 27 milhões dos 96 milhões dos brasileiros com acesso aos serviços de esgoto; os quase 70 milhões de habitantes com acesso são, como vimos, das classes
A, B e C.

Examinando a questão do ponto de vista dos domicílios atendidos com este serviço, a mesma concentração pode ser observada, como é visto na Tabela 4.

\section{Tabela 4 - Acesso dos Domicílios Brasileiros aos Serviços de Esgoto, por Classe de Renda, em 2009}

\begin{tabular}{lccc}
\hline Classe de renda & Taxa de acesso & $\begin{array}{c}\text { \% dos domicílios } \\
\text { com acesso a esgoto }\end{array}$ & $\begin{array}{c}\text { Quantidade de domicílios } \\
\text { com acesso a esgoto }\end{array}$ \\
\hline Classe E & 33,91 & 7,36 & 2.347 .953 \\
Classe D & 41,15 & 15,25 & 4.689 .710 \\
Classe C & 56,84 & 58,40 & 17.964 .151 \\
Classe A,B & 72,35 & 18,72 & 5.758 .838 \\
Brasil & 53,14 & 100,00 & 30.760 .652 \\
\hline
\end{tabular}

Fonte dos dados originais: PNAD/IBGE. Cálculos feitos pelo Centro de Políticas Sociais/FGV.

Conforme mencionado acima, o acesso aos serviços de esgoto depende não apenas da demanda por estes serviços (a qual depende, por sua vez, da capacidade de pagamento da população demandante), mas também da existência das redes de coleta do esgoto e do tratamento deste esgoto coletado. Para isso, são necessários investimentos nos municípios, suprindo tais necessidades. A Tabela 5 a seguir registra a ocorrência destes serviços nos municípios brasileiros. 


\begin{tabular}{|c|c|c|c|c|}
\hline Região & $\begin{array}{l}\text { Quantidade } \\
\text { total de } \\
\text { municípios }\end{array}$ & $\begin{array}{l}\text { Quantidade } \\
\text { de } \\
\text { domicílios } \\
\text { conectados } \\
\text { à rede de } \\
\text { esgoto }\end{array}$ & $\begin{array}{l}\text { Quantidade } \\
\text { de domicílios } \\
\text { conectados à } \\
\text { rede de } \\
\text { esgoto, com } \\
\text { tratamento }\end{array}$ & $\begin{array}{c}\text { Quantidade } \\
\text { de domicílios } \\
\text { conectados à } \\
\text { rede de } \\
\text { esgoto, sem } \\
\text { tratamento }\end{array}$ \\
\hline Norte & 449 & 60 & 34 & 26 \\
\hline Nordeste & 1.793 & 819 & 341 & 478 \\
\hline Sudeste: & 1.668 & 1.586 & 808 & 778 \\
\hline Minas Gerais & 853 & 781 & 194 & 587 \\
\hline Espírito Santo & 78 & 76 & 54 & 22 \\
\hline Rio de Janeiro & 92 & 85 & 54 & 31 \\
\hline São Paulo & 645 & 644 & 506 & 138 \\
\hline Sul & 1.188 & 472 & 286 & 186 \\
\hline C.Oeste & 466 & 132 & 118 & 14 \\
\hline Brasil & 5.564 & 3.069 & 1.587 & 1.482 \\
\hline
\end{tabular}

Fonte dos dados básicos: IBGE, Pesquisa Nacional de Saneamento Básico, 2008.

A Tabela 5 registra, com os dados disponíveis mais atuais (2008), que, dos 5.564 municípios brasileiros, apenas 3.069 deles estavam conectados a uma rede coletora de esgoto. Isto significa que em cerca de 2.500 deles, o esgoto era simplesmente despejado de alguma forma no meio ambiente, na melhor das hipóteses em fossas, mas certamente muitos apenas deixando-o correr pelos terrenos, agravando o problema de poluição ambiental nos municípios. Para piorar a situação, mesmo naqueles municípios nos quais havia redes coletoras de esgoto, apenas na metade havia algum tipo de tratamento, pois na outra metade o esgoto coletado pela rede era simplesmente desviado, transportado para outras áreas e despejado diretamente em rios, lagos e lagoas, mar etc. Mesmo em estados mais desenvolvidos do país, como São Paulo, Rio de Janeiro e Minas Gerais, ainda existem municípios cujos esgotos coletados não recebem qualquer tratamento.

Conforme mencionado anteriormente, a falta de saneamento adequado contribui para um precário quadro de saúde que se reflete nas mortes provocadas pela ausência deste serviço. Por exemplo, um estudo econométrico feito para estimar a causa 
epidemiológica no país mostra que, além de outros fatores, houve uma redução significativa da mortalidade infantil no Brasil causada por doenças que têm relação com a qualidade dos serviços de saneamento e que a maior cobertura destes serviços tornaria possível diminuir os custos de tratamento destas doenças a um custo equivalente ao que se gastaria para incrementar a cobertura. ${ }^{3}$ Este estudo possibilitou constatar que um aumento de $1 \%$ no nível de acesso a estes serviços permitiria a salvação de 216 crianças. Assim, não resta dúvida quanto a importância de lutar para que o nível de universalização dos diversos tipos de serviços de saneamento atinja um melhor índice.

\section{NECESSIDADE DE USO DE INCENTIVOS FINANCEIROS NA AMPLIAÇÃO DA OFERTA DOS SERVIÇOS DE SANEAMENTO}

Os diagnósticos feitos sobre a disponibilidade de serviços de infraestrutura social básica sempre apontam para a dificuldade no Brasil de a população mais pobre conseguir pagar integralmente os custos de provisão dos mesmos e também a impossibilidade de ofertá-los de forma universal no país. Este é o caso particular dos serviços de saneamento básico. Na melhor das hipóteses, parte da população é capaz de pagar a conta de água, mas não dispõe de recursos financeiros para uma conta que inclua todos os custos: o da provisão da água e mais os da coleta das águas servidas e o seu tratamento. Por outro lado, na impossibilidade de obter o financiamento dos custos via cobrança de todos eles, as empresas de saneamento limitam a expansão das suas redes de coleta de esgoto e a instalação de tratamento do mesmo; investimentos em coleta e tratamento de esgoto elevam os custos das empresas, sem retorno financeiro que cubra as suas despesas.

No caso das dificuldades de pagamento das famílias mais pobres, as empresas de saneamento têm colaborado, no limite da sua disponibilidade financeira, reduzindo as tarifas ou mesmo cobrando uma "tarifa social", esta teoricamente capaz de ser paga por aquelas famílias. ${ }^{4}$ Entretanto, mesmo assim, são muitos os domicílios de famílias pobres que continuam sem ter conexão com os serviços de saneamento, particularmente a coleta de esgoto. Assim, é preciso fazer algo mais, subsidiando aquelas famílias, encontrando alguma maneira que lhes permita o acesso a serviços básicos fundamentais.

Para enfrentar as dificuldades das empresas de saneamento em ampliar as suas redes de serviços de esgoto em consonância com a ampliação do acesso em geral da população às redes de serviços de esgoto, particularmente a população pobre, também é necessário aumentar o subsídio que recebem do governo com esta finalidade, mas gerando maior eficiência no uso dos recursos financeiros e concentrando os investimentos de forma preferencial nas populações mais pobres.

É importante chamar a atenção para a questão do foco porque é preciso fazer com que efetivamente os investimentos subsidiados ocorram de forma a disponibilizar o acesso às redes coletoras (e que o esgoto coletado seja tratado) para os domicílios de famílias que não possam pagar para financiar o investimento e os custos destes serviços via pagamento de taxas de conexão e tarifas. Os investimentos tradicionais neste setor, usando empréstimos subsidiados providos pelo setor público, nem sempre estão voltados para atender a este requisito, fazendo com que a expansão dos serviços se faça para áreas que não deveriam se beneficiar de uma política de subsídio social. Neste caso, ocorre um desperdício de subsídio, para quem não necessita do mesmo, e assim as avaliações feitas pelo setor que possibilitou o empréstimo tendem a ser apenas quantitativas, como quantos quilômetros a mais de redes foram construídos e/ou quanto foi gasto no financiamento.

Outro tipo de financiamento, não tradicional, que vem sendo utilizado para investimentos subsidiados em diversos setores produtivos, e focado no efetivo objetivo que motivou ou justificou a sua concessão, é o chamado "output-based aid" (OBA), o qual aumenta a eficiência do investimento e assegura que o objetivo foi atingido. Este tipo de financiamento deve ser utilizado de forma complementar aos projetos 
que ajudam a financiar investimentos nas áreas da infraestrutura social em geral, as quais necessitam do apoio governamental para realizar os seus investimentos.

Projetos que se candidatam a receber o tipo de incentivo financeiro do tipo OBA se caracterizam por realizar o investimento programado e por receber um "prêmio" baseado no montante gasto, na medida em que comprovem que o objetivo foi atingido. Assim, o "prêmio" se constitui em uma devolução, total ou parcial, um subsídio, à empresa que realizou o investimento. Por exemplo, um projeto OBA na área de saneamento seria aquele em que uma empresa realizou os trabalhos de expansão da rede coletora e comprovou que ocorreu uma programada expansão de conexões domiciliares. ${ }^{5}$

Incentivos do tipo OBA vêm sendo aplicados a muitos investimentos na infraestrutura, mesmo na infraestrutura social, em todo o mundo, como forma de induzir os provedores de serviços a aplicar seus recursos financeiros na expansão da oferta destes serviços de maneira a garantir que os investimentos redundem em comprovada utilização final de acordo com o objetivo desejado, na maioria das vezes de forma a atingir efetivamente os pobres. ${ }^{6}$ Várias instituições, principalmente o Banco Mundial, têm apoiado este tipo de financiamento, sendo que várias entidades internacionais (como o próprio Banco Mundial) vêm trabalhando de forma conjunta para divulgar as vantagens deste mecanismo, tendo criado um grupo de suporte para orientar e apoiar financeiramente investimentos deste tipo, o The Global Partnership on Output-Based Aid (GPOBA). ${ }^{7}$ Várias publicações do GPOBA relatam as experiências do emprego do método OBA em setores da infraestrutura básica social, inclusive na área de saneamento. Outras agências têm procurado introduzir o mecanismo OBA no apoio financeiro que têm dado a países menos desenvolvidos nas áreas de saneamento e também em vários outros setores.

Um dos working papers publicados pelo GPOBA divulga a experiência da aplicação do mecanismo OBA em projetos em toda a cadeia de atividades do setor de saneamento. ${ }^{8}$ Alguns dos projetos são os seguintes:

1) Subsídios do tipo OBA concedidos para investimentos na construção de infraestrutura de coleta e tratamento de esgoto em Dacar, no Senegal, voltados para atender às necessidade destes serviços em áreas urbanas pobres e em áreas periféricas da capital. A experiência mostrou-se menos eficaz do que o esperado por diversos motivos, entre os quais o fato de que a crise econômica por que passa o país tornou difícil a decisão das famílias em pagar as suas contas de saneamento ou outras despesas familiares prioritárias, como a alimentação e demais gastos essenciais;

2) Em Moçambique, o projeto de expansão de equipamento de uso familiar (latrinas) tem sido apoiado na forma de resultados comprovados pelas empresas;

3) Na Índia, um programa amplo de construção de latrinas pelas próprias famílias interessadas e de redução de despejo dos resíduos na natureza tem empregado o mecanismo OBA para incentivar a família (o provedor do serviço) a se envolver na resolução do seu problema sanitário;

4) No Egito, um projeto tem o apoio técnico do GPOBA para explorar a possibilidade de aumentar as conexões a estações de tratamento de esgoto. Este projeto fundamenta-se no fato de que as famílias têm uma baixa disponibilidade para arcar com estas conexões porque preferem pagar pela limpeza periódica de suas fossas do que custear a conexão à rede. A solução utilizada foi conceder um subsídio provisório às famílias para que elas peçam a conexão e tornem assim viável a operação das estações de tratamento de esgoto. Entretanto, esta viabilidade dependia ainda de aumento a ser dado às tarifas de uso de água e de esgoto para viabilizar financeiramente a empresa de saneamento, o que ainda não foi possível fazer estando o projeto paralisado aguardando uma solução;

5) No Quênia, um projeto-piloto foi estabelecido inicialmente para o abastecimento de água, sendo mais tarde estendido para a coleta de esgoto e tratamento. O projeto é financiado por empréstimos e 
posteriormente, com a finalização bem sucedida, um subsídio é pago à empresa de forma a cobrir parte dos custos do mesmo (o empréstimo inicial). Este subsídio reduz então o valor do empréstimo a ser pago, diminuindo o serviço da dívida (juros e amortizações) e também reduzindo a tarifa de uso cobrada aos consumidores. Este tipo de apoio reduz o risco do investimento e aumenta o incentivo para que o projeto seja completado com o acréscimo do numero de conexões e com o incremento da receita da empresa.

6) No Marrocos, um projeto tipo OBA foi estabelecido para prover conexões na distribuição de água e na coleta de esgoto em áreas com habitações irregulares. O produto (resultado) medido deste projeto é a ligação simultânea das conexões de água e de esgoto advindas da implementação do investimento. O subsídio pago à empresa pelas conexões comprovadas é pago em duas partes, uma correspondente a $60 \%$ do subsídio, logo após a comprovação, e a segunda parte, $40 \%$, após a verificação de que a conexão permaneceu ligada nos seis meses seguintes, como forma de forçar a sustentabilidade do projeto.

7) Projetos implantados no Chile e na Colômbia para aumentar as conexões à rede de abastecimento de água via subsídios tipo OBA para usuários de menor renda complementam os subsídios dados ao consumo de forma a tornar possível o pagamento das contas de água por usuários desta classe social. Projeto desta natureza foi implantado em outros países também com a finalidade de ser uma etapa de transição para uma tarifação do tipo cost-recovery a fim de assegurar a sustentação financeira da empresa de saneamento.

8) Implantação de projetos OBA em alguns países, como a Índia e Bangladesh, para a instalação de banheiros públicos e comunitários em áreas faveladas e de ocupação informal.

Os exemplos acima, recolhidos na literatura sobre projetos OBA, demonstram que sua utilização não é uma novidade, pois a ideia vem sendo empregada em diversos países. Na realidade, mesmo para o Brasil, seu emprego não constitui uma novidade porque a experiência do seu emprego pelo PRODES também está disponível. O que se requer é que a experiência do PRODES seja preservada e ampliada com o objetivo de universalizar os serviços de saneamento, particularmente a expansão das redes de esgoto e o tratamento do esgoto, e para que possa ser atingida com maior brevidade e com mais eficiência. Como já reiterado anteriormente, a justificativa para isso é o desenvolvimento social da população brasileira e a melhoria das condições ambientais do país.

A Agência Nacional de Águas (ANA), agência reguladora brasileira, é uma autarquia federal vinculada ao Ministério do Meio Ambiente, responsável pela implementação da gestão dos recursos hídricos brasileiros. Tem como missão regular o uso das águas dos rios e lagos de domínio da União e implementar o Sistema Nacional de Gerenciamento de Recursos Hídricos. Esta agência criou em 2000 e iniciou em 2001 a implementação do PRODES (Programa de Despoluição de Bacias Hidrográficas) ao selecionar projetos para empregar recursos em apoio à construção de estações de tratamento de esgotos. A ideia do PRODES é empregar o método OBA em projetos municipais deste tipo para atingir os objetivos de captação e tratamento de esgotos de forma eficiente. Os recursos financeiros do PRODES têm origem no orçamento da União, sendo empregados em projetos que passam por um processo de seleção que escolherá que projetos apoiar. A seleção, feita anualmente, dos projetos apresentados pelos municípios/empresas que se candidatam, visa não apenas adequar a disponibilidade dos recursos financeiros disponíveis para esta finalidade à demanda dos mesmos, mas principalmente assegurar a qualidade dos projetos e a efetiva possibilidade de sua execução. Em função da comprovação pela empresa de saneamento de que os objetivos foram materialmente atingidos (ou seja, que a estação de tratamento foi construída, está em funcionamento há um determinado tempo, apresentando os parâmetros técnicos previstos e que o número estabelecido de conexões à rede de coleta de esgotos foi alcançado), 
o PRODES concede um prêmio à empresa de saneamento. Nestes termos, o PRODES não é um fundo que financie projetos. O PRODES devolve à empresa parte dos gastos (entre $30 \%$ a $100 \%$, respectivamente, para projetos de grande dimensão e para projetos de pequena dimensão) que esta teve com a obra se for comprovado que os objetivos foram atingidos. Com isto, pode-se entender que o PRODES teria subsidiado metade dos custos empregados na obra. ${ }^{9}$ Porém, é importante ressaltar que o programa não está fundamentado na execução da obra, mas na comprovação do resultado da obra, que é a ideia básica do incentivo tipo OBA. Desta forma, assegurase que o projeto implementado tem alta possibilidade de atingir o seu objetivo, daí a sua importância.

Mais recentemente, o PRODES resolveu empregar uma ponderação maior na avaliação dos projetos àqueles que se refiram a áreas críticas (elevados níveis de poluição ambiental provocados pelo despejo in natura de esgoto sem tratamento).

É importante ressaltar que, embora os projetos submetidos ao PRODES se refiram àqueles voltados para a execução e a operação de tratamento de esgotos, estes projetos certamente têm outros componentes relativos à necessidade de a empresa de saneamento fazer os demais investimentos de saneamento, que vão permitir que as metas relacionadas com o tratamento de esgoto se materializem.

A experiência do PRODES tem sido bem avaliada. A possibilidade de premiação tem estimulado bastante as empresas de saneamento a apresentarem seus projetos ao programa.

\section{NECESSIDADE DE USO DE INCENTIVOS FINANCEIROS (SUBSÍDIO) À DEMANDA POR SERVIÇOS DE SANEAMENTO}

Já foi mencionado anteriormente que as empresas de saneamento têm procurado facilitar o acesso das famílias pobres à totalidade dos serviços de saneamento aliviando os custos das contas de consumidores mais pobres, estimulando inclusive as ligações de seus domicílios à rede de coleta de esgoto (quando estas redes estão disponíveis) cobrando tarifas menores a estes consumidores. ${ }^{10}$ Isto, entretanto, não tem acontecido, pois mesmo no caso da disponibilidade há consumidores pobres que não se dispõem a ter a sua residência ligada à rede.

Pela importância que o saneamento tem do ponto de vista social (melhorando as condições de vida dos moradores e reduzindo a possibilidade de doenças associadas à ausência ou à deficiência de tal serviço) e do ponto vista ambiental (diminuindo a agressão ao meio ambiente e ampliando a defesa dos recursos hídricos do país), a situação descrita tem que ser enfrentada permitindo custo zero ao uso dos serviços para remover todos os empecilhos de demanda que existirem. Neste caso, isto significa custo zero para os consumidores pobres, no tocante aos serviços de saneamento. Obviamente, a provisão destes serviços tem um custo, o qual terá que ser coberto para evitar que a empresa de saneamento, pública ou privada, seja penalizada na sua receita pela não cobrança aos consumidores pobres. A não cobrança será uma forma de subsídio dado a estes consumidores, que agora poderão usar os serviços de saneamento sem as restrições de orçamento que normalmente condicionam suas escolhas. ${ }^{11}$

Assim, será necessário que as empresas mantenham um cadastro de consumidores com estas características. Em outras palavras, deve-se identificar as famílias pobres a quem será oferecido o subsídio, verificar periodicamente esta identificação para confirmar se persistem as condições sociais das famílias beneficiárias.

Outra necessidade evidente é encontrar a forma pela qual o subsídio será concedido, quem o financiará e a forma menos complexa de administrar este benefício. Na seção que se segue será feita uma sugestão que responde a tais questões.

\section{Elementos para a Definição de um Programa de Expansão do Acesso das Famílas Pobres aOS Serviços de Saneamento no Brasil}

Em função de tudo que foi escrito nos parágrafos anteriores deste texto, particularmente nas seções III e IV, pode-se sugerir ao governo federal o 
estabelecimento de um programa para aumentar o acesso das famílias pobres no Brasil aos serviços de saneamento.

No que tange à definição do público-alvo, o foco do programa, pode-se pensar na utilização do cadastro único do programa Bolsa Família. Este cadastro tem em seus registros informações detalhadas sobre as famílias pobres e extremamente pobres inscritas, contendo atualmente mais de 12 milhões de beneficiários deste programa. O programa Bolsa Família prevê um benefício monetário mínimo transferido aos inscritos no mesmo, visando reduzir a pobreza e a desigualdade de renda e também diminuir a transmissão intergeracional de pobreza. É um programa federal de transferência condicionada de renda aos pobres do país, semelhante a outros programas de mesma natureza utilizados por governos da América Latina. As condicionantes para a manutenção da transferência de renda aos beneficiários são a frequência escolar para crianças e adolescentes, e outros critérios relacionados à rotina de alimentação e saúde da família.

A ideia de usar o cadastro único do programa Bolsa Família se prende ao fato de que lá estão registradas todas as famílias pobres e extremamente pobres do Brasil, e ao fato de possivelmente muitas destas famílias morarem em domicílios carentes de acesso aos serviços de saneamento. Portanto, será possível identificar com muita clareza onde estão os domicílios com este tipo de carência, quais são estas famílias, quantas são, verificar a existência ou não de redes de abastecimento de água potável e de coleta de esgoto, definir as necessidades de expansão e de criação destas redes e estabelecer a necessidade de investimentos que serão requeridos para disponibilizar a infraestrutura de água e saneamento.

Como não basta prover esta infraestrutura, sendo também necessário dar condições financeiras a estas famílias de pagar pelo seu uso, o que se pensa é que seria importante que os recursos necessários para o pagamento da conta viessem de uma bolsa concedida a estas famílias no valor exato da mesma. Em outras palavras, as famílias pobres e extremamente pobres participantes de um programa de universalização dos serviços de saneamento receberiam uma ajuda financeira complementar na forma de uma bolsa no valor suficiente para quitar a sua conta mensal com a empresa de saneamento local. Esta bolsa resolveria a questão do lado da demanda destas famílias pelos serviços de saneamento, pois não haveria mais a restrição orçamentária que impediria o seu acesso.

É importante ressaltar que um subproduto importante do uso de uma bolsa de saneamento é permitir que as empresas possam cobrar os custos dos serviços. Atualmente, dos 3.069 municípios com esgotamento sanitário no país, apenas 1.682 deles cobram pelos serviços, qual seja, 1.377 municípios nada arrecadam para cobrir os custos que a coleta do esgoto gera. Isto é uma perda de arrecadação para estas empresas, cujo desempenho financeiro melhoraria com a receita proveniente da bolsa saneamento.

Do lado da oferta, sugere-se que seja usado um esquema do tipo OBA para permitir que os municípios/empresas possam fazer os investimentos necessários para prover a expansão das redes e o tratamento do esgoto nos municípios e áreas integrantes deste programa de universalização dos serviços de saneamento. Além da necessidade dos governos municipais, estadual e federal ampliarem as suas dotações orçamentárias para financiar este tipo de investimento, é preciso que este programa empregue a mesma metodologia para a avaliação dos projetos a serem estimulados via esquema do incentivo OBA. Isto objetivaria não apenas devolver total ou parcialmente os recursos financeiros empregados nas obras e assim estimular o investimento, mas também garantir que o programa estaria atingindo de forma concreta as famílias pobres e extremamente pobres participantes do programa, ao mesmo tempo em que certificaria que os investimentos teriam a qualidade técnica combinada na sua contratação.

O que se está propondo, portanto, é o uso simultâneo do esquema ou mecanismo do tipo OBA nos investimentos demandados por este programa de universalização dos serviços de saneamento no país 
e o uso complementar de uma bolsa saneamento, a qual seria criada para permitir que os beneficiários daquele programa sejam capazes de demandar, no sentido econômico, esses serviços.

Já foram mencionados os benefícios que um programa como o sugerido podem provocar nas condições de vida da população mais pobre do país. Não é demais lembrar que os efeitos do programa não se esgotam com a melhoria das condições de saúde e de bem estar desta população, pois o lado ambiental também seria contemplado pela diminuição da degradação dos nossos recursos hídricos. É necessário que haja consciência da importância que um programa como este tem, para que a população e os políticos possam dar-lhe o merecido apoio, com o objetivo de sua tão desejada quanto útil concretização.

\section{NotAs e RefERÊnCIAs BibLIOGRÁficAs}

${ }^{1}$ As ideias expostas neste texto estão fundamentadas com maior profundidade em um artigo e um relatório, respectivamente, de Neri e Andrade (2011) e Neri, Andrade, Melo, Sacramento, De Cas, Lipkin, Carvalho e Moreira

(2011).

${ }^{2}$ No caso da telefonia, a grande evolução dos serviços de telefone celular no período, em certa medida, veio resolver a enorme escassez de telefones fixos nos domicílios.

${ }^{3}$ Artigo de Mendonça e Seroa da Motta (2007), Saúde e Saneamento no Brasil.

${ }^{4}$ As empresas de saneamento no Brasil geralmente usam uma estrutura tarifária com preços marginais crescentes por faixas crescentes de consumo de água, portanto, cobrando tarifas mais baixas aos usuários que menos consomem. O pressuposto é que as famílias pobres consomem mensalmente menos água e, assim, seu consumo estaria sendo subsidiado por meio de um esquema de subsídio cruzado entre usuários. Esta forma de cobrança tem muito a ser melhorada se o objetivo é usar a tarifa de água para redistribuir renda real entre as famílias. Ver, por exemplo, as análises feitas por Andrade, (1995) neste livro que é a tradução da sua dissertação doutoral para o University College, London. Outros artigos que tratam do mesmo tema, escritos pelo mesmo autor, estão registrados na seção de referências bibliográficas desta apresentação.

5 Os parágrafos seguintes que exemplificam a utilização do incentivo OBA em diversos países foram reproduzidos do relatório final do estudo piloto do estudo "Brasil: Subsídio aos Serviços de Saneamento para População de Baixa Renda com Base em Resultados", escrito para o Banco Mundial por Neri, Andrade e outros (2011).
${ }^{6}$ Projetos do tipo OBA têm sido empregados, por exemplo, em telecomunicações e na manutenção de rodovias, entre outros setores.

${ }^{7} \mathrm{O}$ Banco Mundial apoiou o financiamento de 33 projetos do tipo OBA no setor de abastecimento de água e de coleta e tratamento de esgotos até recentemente (setembro de 2010), sendo que 24 projetos são para abastecimento de água, 3 para coleta e tratamento de esgoto e 6 para ambos os serviços.

${ }^{8} \mathrm{O}$ trabalho a que se faz menção é o Output-Based Aid for Sustainable Sanitation, de Sophie Trémolet e Barbara Evans, com a ajuda de David Schaub-Jones, OBA Working Paper Series, GPOBA Paper no 10, September 2010. A descrição que se segue usa o texto referido como base de referência e por isso se reconhece a contribuição dos citados autores quanto à originalidade do seu trabalho.

${ }^{9} \mathrm{Na}$ realidade, a empresa de saneamento necessita ter os meios para realizar o projeto, não podendo contar com os recursos do PRODES, pois estes só lhe serão repassados no futuro, parcialmente, se o projeto receber a premiação do PRODES. O município ou a empresa provavelmente terá que conseguir os recursos por meio de uma transferência negociada com o governo federal ou algum empréstimo subsidiado para executar a obra.

${ }^{10} \mathrm{Na}$ realidade, em geral as empresas de saneamento no Brasil usam o critério de cobrar um adicional percentual sobre o valor da conta do consumo de água para se ressarcir quando o domicílio é ligado à rede de esgoto.

${ }^{11}$ A teoria econômica nos ensina que, quando o preço de um bem ou serviço é zero, há possibilidade de desperdício por parte do consumidor. Neste caso, a empresa de saneamento pode limitar o subsídio aos custos de saneamento aos consumidores pobres cujo gasto vai até uma determinada quantidade mensal de água; assim, a quantidade esgotada também ficará limitada e os custos de tratamento também serão limitados.

ANDRADE, T. A. As Tarifas dos Serviços Públicos e a Pobreza. Revista Brasileira de Economia, Rio de Janeiro, v. 48, p. 371-387, jul. /set. 1994.

Aspectos Distributivos na Determinação de Preços Públicos. Rio de Janeiro: IPEA, 1995.

. A Oferta Privada de Serviços Públicos e a Determinação de Preços com Objetivos Sociais. Pesquisa e Planejamento Econômico, v. 25, p. 223-240, abr. 1995.

Redistribuição de Renda via Tarifas dos Serviços Públicos. Nova Economia: Revista da Faculdade de Ciências Econômicas da UFMG, Belo Horizonte, v. 5, n. 1, p. 23-40, ago. 1995.

- Privatização e Regulação das Tarifas das Empresas Prestadoras de Serviços Públicos. Economia Brasileira em Perspectiva: publicação do IPEA, Rio de Janeiro, cap. 31, p. 717-724, 1996.

ANDRADE, T. A.; LOBÃO, W. J. A. Tarifação Social no 
Consumo Residencial de Água. Economia Aplicada: Revista da Faculdade de Economia, Administração e Contabilidade de Ribeirão Preto da Universidade de São Paulo, São Paulo, v.1, n. 1, p. 59-80, jan./mar. 1997.

MENDONÇA, M. J. C.; SEROA DA MOTTA, R. Saúde e Saneamento no Brasil. Planejamento e Políticas Públicas, v. 30, p.15-30, jun./dez. 2007.

NERI, M. C.; ANDRADE, T. A. Cadastro Social Único e Incentivos à Universalización de Servicios de Utilidad Pública in Brasil. In: Inversión en Infraestructura Pública y Reducción de la Pobreza en América Latina. Rio de Janeiro: Konrad Adenauer Stiftung, 2011. p. 65-86.

NERI, M. C. et al. Brasil: Subsídio aos Serviços de Saneamento para População de Baixa Renda com Base em Resultados. Relatório Final do Estudo Piloto. Rio de Janeiro: Centro de Políticas Sociais da Fundação Getúlio Vargas, junho de 2011.

TRÉMOLET, S.; EVANS, B. com a ajuda de SCHAUB-JONES, D. Output-Based Aid for Sustainable Sanitation, OBA Working Paper Series, GPOBA Paper n 10, nov. 2010. 